\title{
Rubella immunity among pregnant women in a Canadian provincial screening program
}

\author{
Mark J Kearns BSc${ }^{1}$, Sabrina S Plitt $\mathrm{PhD}^{2}$, Bonita E Lee MD MSc ${ }^{3}$, Joan L Robinson $\mathrm{MD}^{3}$
}

MJ Kearns, SS Plitt, BE Lee, JL Robinson. Rubella immunity among pregnant women in a Canadian provincial screening program. Can J Infect Dis Med Microbiol 2009;20(3):73-77.

BACKGROUND: There are limited recent data on rubella immunity in women of childbearing age in Canada. In the present paper, the proportion of rubella seroreactivity and redundant testing (testing of women previously seropositive when tested by the same physician) in the Alberta prenatal rubella screening program were studied.

METHODS: In the present retrospective observational study, data on all specimens submitted for prenatal screening in Alberta between August 2002 and December 2005 were extracted from the Provincial Laboratory for Public Health database. The proportion of rubella screening and immunoglobulin $\mathrm{G}$ ( $\mathrm{IgG}$ ) seroreactivity were determined. Demographic variables were compared between rubella seroreactors and nonseroreactors. The proportion of redundant testing was determined. RESULTS: Of 159,046 prenatal specimens, $88.3 \%(n=140,473)$ were screened for rubella immunity. In total, $8.8 \%$ of specimens tested negative for rubella IgG. Younger women $(23.2 \%$ of women younger than 20 years of age versus $4.7 \%$ of women between 35 and 39 years of age; $\mathrm{P}<0.001)$ and women from northern Alberta $(11.9 \%$ versus $8.1 \%$ [overall]; $\mathrm{P}<0.001$ ) were significantly more likely to have seronegative specimens. Of the 20,044 women who had multiple rubella immunity screenings, $88.1 \%(\mathrm{n}=17,651)$ had multiple positive test results. In total, $20.7 \%$ of the 42,274 specimens submitted from women with multiple screenings were deemed redundant.

DISCUSSION: Younger women were most likely to be seronegative for rubella. The public health significance of women entering their childbearing years with low or undetectable rubella IgG levels remains to be determined. A large number of women with documented rubella immunity were unnecessarily retested.

Key Words: Immunity; Pregnancy; Rubella; Screening

$\mathrm{R}$ ubella infection typically manifests as a benign illness with fever, lymphadenopathy and rash. More serious manifestations, such as arthritis and encephalitis, are rare. Congenital infection before 16 weeks' gestation can result in congenital rubella syndrome (CRS) with sequelae such as deafness, cardiac disease, cognitive impairment and ocular disease (1-4). During the rubella pandemic (1962 to 1965), 11,000 fetal deaths and 20,000 cases of CRS occurred in the United States alone (5). CRS still presents a significant global health challenge, with an estimated minimum of 100,000 cases occurring annually worldwide (6). However, between 1996 and 2004, the number of countries having a rubella vaccination program increased from 78 to 116 among the 192 countries reporting to the World Health Organization (7). Since Canada implemented

\section{Immunité contre la rubéole chez des femmes enceintes inscrites à un programme de dépistage provincial au Canada}

HISTORIQUE : On dispose de peu de données récentes sur l'immunité
contre la rubéole chez les femmes fertiles au Canada. Dans le présent
article, la proportion de séroréactivité contre la rubéole et de tests
redondants (tests effectués par le même médecin chez des femmes ayant
déjà affiché une séropositivité) a été analysée par le programme albertain
de dépistage prénatal de la rubéole.
MÉTHODES : Dans la présente étude d'observation rétrospective, les
données sur tous les spécimens soumis pour dépistage prénatal en Alberta
entre août 2002 et décembre 2005 ont été extraites de la base de données
du laboratoire provincial de santé publique. Les auteurs ont calculé la
proportion de tests de dépistage de la rubéole et de cas de séroréactivité à
l'immunoglobuline G (IgG). Ils ont comparé les variables démographiques
selon que les patientes manifestaient ou non une séroréaction à la rubéole
et calculé la proportion de tests redondants. RÉSULTATS : Parmi les 159046 spécimens prénataux, 88,3\% (n = 140473 ) ont été soumis à un dépistage de l'immunité contre la rubéole. En tout, $8,8 \%$ des spécimens ont produit des résultats négatifs pour ce qui est de l'IgG de la rubéole. Les femmes plus jeunes (23,2 \% des femmes de moins de 20 ans, contre $4,7 \%$ des femmes de 35 à 39 ans, p < 0,001) et les femmes du Nord de l'Alberta $(11,9 \%$ vs $8,1 \%$ [global], $\mathrm{p}<0,001)$ étaient significativement plus susceptibles de présenter des spécimens séronégatifs. Parmi les 20044 femmes ayant subi plus d'un test de dépistage de l'immunité contre la rubéole, 88,1\% ( $\mathrm{n}=17$ 651) ont maintenu leurs résultats positifs. En tout, 20,7 \% des 42274 spécimens soumis provenant de femmes ayant subi plus d'un test de dépistage ont été jugés redondants. DISCUSSION : Les femmes jeunes étaient plus susceptibles d'être séronégatives à l'égard de la rubéole. Il reste à déterminer la portée de ces taux faibles ou indécelables d'IgG de la rubéole chez les femmes qui débutent leurs années de fertilité pour la santé publique. Un nombre important de femmes dont l'immunité contre la rubéole avait déjà été documentée ont subi des tests superflus.

its vaccination program in 1969 , rubella incidence has dramatically decreased such that only 29 rubella cases were reported in 2000, although more than 220 cases were subsequently reported in a 2005 outbreak in an unimmunized community in Ontario (8). In Alberta, a provincial rubella vaccination program was implemented in 1971 as a single-dose vaccine for adolescent females. In 1982, this was changed to a single-dose schedule with the measles, mumps and rubella (MMR) vaccine for all children 12 to 15 months of age, with a second dose of the MMR vaccine being added at four to six years of age in 1996. Compliance with immunization has been consistently greater than $90 \%$ for this government-funded program.

The rubella vaccine is highly efficacious, but rubella immunoglobulin $\mathrm{G}$ (IgG) levels wane over time. It has been

${ }^{1}$ Faculty of Medicine, University of Alberta, Edmonton, Alberta; ${ }^{2}$ Centre for Communicable Disease and Infection Control, Public Health Agency of Canada, Ottawa, Ontario; ${ }^{3}$ Provincial Public Health Laboratory, Edmonton, Alberta

Correspondence: Dr Joan L Robinson, Room 8213, Aberhart One, 11402 University Avenue, Edmonton, Alberta T6G 2J3.

Telephone 780-407-1680, fax 780-407-7136, e-mail jr3@ualberta.ca

Received for publication July 23, 2008. Accepted December 20, 2008 
shown that fewer than $80 \%$ of individuals have protective titres to rubella 13 years postimmunization, based on a singledose vaccine schedule at one year of age (9). Despite the potentially significant proportion of seronegative women, it is possible that many of them have seroreverted and would, nevertheless, mount a booster response if challenged with rubella (7).

The primary objective of the present study was to determine the proportion of nonimmune rubella titres in pregnant women in Alberta and to identify factors associated with rubella seronegativity to guide future rubella immunization and screening programs. The secondary objective was to determine the extent of redundant prenatal rubella screenings to plan interventions that could decrease laboratory costs.

\section{METHODS}

In Alberta, since August 2002, all prenatal screenings for antibodies to rubella, varicella, syphilis, HIV and the presence of hepatitis B surface antigen were performed centrally at the Provincial Laboratory for Public Health database (ProvLab). The rubella screening is an opt-out program because physicians are advised that women with documentation of previous rubella immunity or women who have received two doses of the rubella vaccine should not have rubella serology requested. This decision by the physician to opt out of rubella IgG testing is indicated by marking a check box on the prenatal requisition.

In the present retrospective observational study, routine prenatal specimens submitted from Alberta residents between August 1, 2002, and December 31, 2005, were included in the present study. Data on age, health region of residence, gravidity and parity were extracted from the prenatal testing requisition for all specimens. Gravidity and parity were only recorded on $62.0 \%$ and $60.2 \%$ of prenatal requisitions, respectively. Approximately two-thirds of the 3.2 million Albertans reside in either Edmonton or Calgary, with the remaining one-third distributed across the rest of the province. For analysis, the provincial health regions were divided into four geographical areas - two urban areas: Calgary (region 3) and Edmonton (region 6); and two largely nonmetropolitan areas: northern Alberta (regions 5, 7, 8 and 9) and southern Alberta (regions $1,2$ and 4$)$.

Testing for quantitative rubella $\operatorname{IgG}$ was performed on an automated platform (AxSYM, Abbott Laboratories, USA) and reported as positive for levels greater than $15 \mathrm{U} / \mathrm{mL}$ and negative for levels lower than $10 \mathrm{U} / \mathrm{mL}$. Up to December 1, 2005, testing was repeated for specimens with IgG levels between $10 \mathrm{U} / \mathrm{mL}$ and $15 \mathrm{U} / \mathrm{mL}$. If both results were greater than $10 \mathrm{U} / \mathrm{mL}$, the specimen was reported as positive for rubella IgG. If the first two tests were discordant (one being lower than $10 \mathrm{U} / \mathrm{mL}$ ), a third test was performed, and two of the three tests were used to determine the final status (negative being two of the three results lower than $10 \mathrm{U} / \mathrm{mL}$ ). Since December 1, 2005, rubella IgG levels between $10 \mathrm{U} / \mathrm{mL}$ and $15 \mathrm{U} / \mathrm{mL}$ were simply reported as indeterminate.

Rubella screening was classified as 'redundant' if a woman was screened subsequent to a positive IgG result while under the care of the same physician. Demographics and reproductive history were compared for the prenatal specimens that were seropositive, seronegative and indeterminate, and specimens

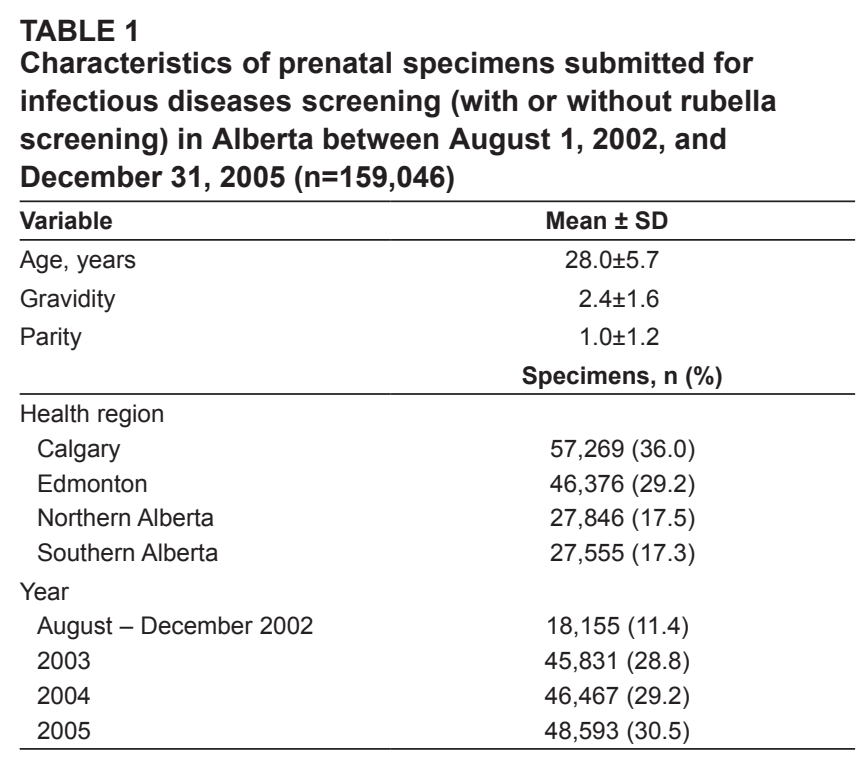

that were deemed nonredundant or redundant. The quantitative rubella titres of the specimens were also analyzed by age. Categorical variables were compared using the $\chi^{2}$ test, and continuous variables were compared with $t$ tests, ANOVA (for means) and the Kruskall-Wallis test (for medians).

All statistical analyses were performed using Stata version 8.0 (StataCorp, USA). Ethics approval for the present study was granted by the Health Research Ethics Boards of the University of Alberta and the University of Calgary.

\section{RESULTS}

Between August 1, 2002, and December 31, 2005, 159,046 specimens were submitted to the ProvLab for prenatal screenings from 129,743 women (Table 1). In total, $79.9 \%$ of women had one prenatal specimen submitted, $17.8 \%$ had two specimens submitted and $2.3 \%$ had three or more prenatal specimens submitted during this time period. Rubella screening was requested on $88.3 \%(n=140,473)$ of the specimens submitted for prenatal testing. The proportion of specimens screened for rubella annually increased from $84 \%$ in 2002 to $90 \%$ in 2005 .

Of all prenatal specimens screened for rubella, $91.0 \%$ $(\mathrm{n}=127,800)$ tested positive, $8.8 \%(\mathrm{n}=12,364)$ tested negative and $0.2 \%(n=280)$ were indeterminate (Table 2). Younger women were more likely to have seronegative specimens; $23.2 \%$ of specimens from women younger than 20 years of age were seronegative versus $4.7 \%$ from women between 35 and 39 years of age $(\mathrm{P}<0.001)$. Primigravid women were more likely to be seronegative than were multigravid women $(9.1 \%$ for primigravid women, $7.4 \%$ for bigravid women and $7.6 \%$ for trigravid women; $\mathrm{P}<0.001$ ). Specimens submitted from the two urban centres had the lowest proportion of seronegative specimens $(7.3 \%$ and $7.9 \%)$, while those from Northern Alberta had the highest proportion of seronegative specimens (11.9\%).

The proportion of rubella seronegativity increased over the years from $8.2 \%$ in 2002 to $9.9 \%$ in $2005(\mathrm{P}<0.0001)$. This increase was most striking for those women between 20 and 24 years of age, among whom the proportion of seronegative specimens increased from $10.3 \%$ in 2002 to $18.3 \%$ in 2005 
TABLE 2

Results of prenatal rubella immunoglobulin G (lgG) testing in Alberta between August 1, 2002, and December 31, 2005

\begin{tabular}{|c|c|c|c|c|c|}
\hline Variable & Specimens, $\mathbf{n}$ & Seropositive & Seronegative & Indeterminate & $\mathbf{P}$ \\
\hline Number of specimens, total & $140,444^{*}$ & $127,800(91.0)$ & $12,364(8.8)$ & $280(0.2)$ & - \\
\hline Age, years & $139,798^{\dagger}$ & $28.1 \pm 5.6$ & $24.4 \pm 5.8$ & $25.5 \pm 5.6$ & $<0.0001$ \\
\hline Age category, years & & & & & $<0.0001$ \\
\hline$<20$ & 15,398 & $11,783(76.5)$ & $3,566(23.2)$ & $49(0.3)$ & - \\
\hline $20-24$ & 26,380 & $22,579(85.6)$ & $3,717(14.1)$ & $84(0.3)$ & - \\
\hline $25-29$ & 44,151 & $41,463(93.9)$ & $2,606(5.9)$ & $82(0.2)$ & - \\
\hline $30-34$ & 36,119 & $34,547(95.7)$ & $1,528(4.2)$ & $44(0.1)$ & - \\
\hline $35-39$ & 14,622 & $13,918(95.2)$ & $689(4.7)$ & $15(0.1)$ & - \\
\hline$\geq 40$ & 3,128 & $2,933(93.8)$ & $190(6.1)$ & $5(0.2)$ & - \\
\hline Gravidity & $88,136^{\dagger}$ & $2.3 \pm 1.6$ & $2.2 \pm 1.7$ & $2.3 \pm 1.6$ & $<0.0001$ \\
\hline Parity & $84,027^{\dagger}$ & $1.0 \pm 1.2$ & $0.8 \pm 1.3$ & $1.0 \pm 1.3$ & $<0.0001$ \\
\hline Median rubella IgG titre, U/mL (IQR) & $140,440^{\ddagger}$ & $56.9(29.5-109.2)$ & $5.7(2.5-7.9)$ & $12.4(10.8-13.6)$ & $<0.0001$ \\
\hline Health region & & & & & $<0.0001$ \\
\hline Calgary & 49,050 & $45,385(92.5)$ & $3,580(7.3)$ & $85(0.2)$ & - \\
\hline Edmonton & 41,039 & $37,697(91.9)$ & $3,258(7.9)$ & $84(0.2)$ & - \\
\hline Northern Alberta & 25,481 & $22,406(87.9)$ & $3,023(11.9)$ & $52(0.2)$ & - \\
\hline Southern Alberta & 24,874 & $22,312(89.7)$ & $2,503(10.1)$ & $59(0.2)$ & - \\
\hline Year & & & & & $<0.0001$ \\
\hline August - December 2002 & 15,247 & $13,990(91.8)$ & $1,253(8.2)$ & $4(0.03)$ & - \\
\hline 2003 & 40,097 & $36,852(91.9)$ & $3,238(8.1)$ & $7(0.02)$ & - \\
\hline 2004 & 41,377 & $37,827(91.4)$ & $3,549(8.6)$ & $1(0.002)$ & - \\
\hline 2005 & 43,723 & 39,131 (89.5) & $4,324(9.9)$ & $268(0.6)^{\S}$ & - \\
\hline
\end{tabular}

Data are represented as $n(\%)$ or mean $\pm S D$. *Of the specimens that were not opted out of the rubella lgG screening ( $n=140,473), 29$ had no result because of problems with testing (eg, insufficient blood sample); ${ }^{\dagger}$ Number of specimens of the 140,444 for which these data were recorded on the requisition; $¥$ Four specimens had an interpreted serological result (positive, negative or indeterminate), but the actual titre was not available; $\$$ The rise in the number of specimens having indeterminate serology in 2005 is due to a change in screening protocol that took effect as of December 1, 2005 (from this poin $t$ onward, rubella lgG levels between $10 \mathrm{U} / \mathrm{mL}$ and $15 \mathrm{U} / \mathrm{mL}$ have been classified as indeterminate). IQR Interquartile range

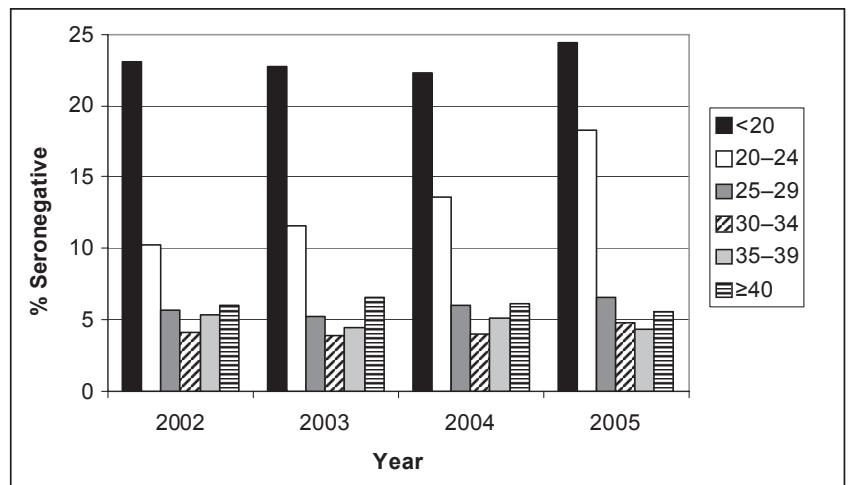

Figure 1) Proportion of specimens (by age group and year ) testing seronegative for rubella immunoglobulin G in Alberta between 2002 and 2005

(Figure 1). Rubella IgG titres increased with age up to the 30-year to 34-year age group (Table 3). A similar trend was seen when only primigravid women were examined; titres significantly increased throughout the age groups (data not shown).

Women with multiple rubella immunity screens (median number of screens = two; range two to six) were examined. Of 20,044 women who had multiple specimens tested for rubella, $17,651(88.1 \%)$ had multiple positive test results, and $1757(8.8 \%)$ had three or more positive test results. In total, $20.7 \%$ of the 42,274 specimens submitted from women with multiple screens were deemed redundant (Table 4). Women with redundant screenings were older than those without
TABLE 3

Patient age category and mean and median rubella immunoglobulin G (lgG) titres for prenatal specimens screened for rubella immunity in Alberta $(n=138,794)^{*}$ between August 1, 2002, and December 31, 2005

\begin{tabular}{lccc}
\hline $\begin{array}{l}\text { Age category, } \\
\text { years }\end{array}$ & Specimens, $\mathbf{n}$ & $\begin{array}{c}\text { Mean rubella IgG } \\
\text { titres, } \mathbf{U} / \mathbf{m L}, \\
\text { mean } \pm \text { SD }\end{array}$ & $\begin{array}{c}\text { Median rubella IgG } \\
\text { titres, } \mathbf{U} / \mathbf{m L}(\mathbf{I Q R})\end{array}$ \\
\hline$<20$ & 15,397 & $34.6 \pm 44.3$ & $21.5(10.8-41.3)$ \\
$20-24$ & 26,380 & $52.3 \pm 61.3$ & $32.7(15.9-65.0)$ \\
$25-29$ & 44,150 & $84.5 \pm 85.6$ & $57.7(28.7-108.2)$ \\
$30-34$ & 36,118 & $101.7 \pm 99.4$ & $69.7(35.4-131.1)$ \\
$35-39$ & 14,621 & $102.9 \pm 105.3$ & $67.5(32.7-132.5)$ \\
$\geq 40$ & 3,128 & $104.4 \pm 111.0$ & $64.9(29.6-134.7)$ \\
\hline
\end{tabular}

*Specimens ( $n=1650$ ) with no informatio $n$ of age were excluded from the analysis. IQR Interquartile range

redundant screenings $(28.4 \pm 5.3$ years versus $27.5 \pm 5.6$ years; $\mathrm{P}<0.0001)$. Northern Alberta had the lowest proportion of redundant screenings $(17.0 \%)$, while Edmonton had the highest $(22.6 \%)$. This trend was independent of the number of screening tests performed per woman. The annual proportion of specimens with redundant screening was similar over the study period.

\section{DISCUSSION}

The present study showed that $8.8 \%$ of prenatal specimens submitted for screening in Alberta lacked reliably protective levels of rubella $\mathrm{IgG}$, and that women in the younger age groups were more likely to be seronegative than the older women. This level 
of seroreactivity is similar to that from a Quebec study (10), which reported that $8.4 \%$ of pregnant women screened in $1993 / 1994$ were seronegative (10); a recent report (11) of $10.2 \%$ seronegativity among female day care workers was also reported in Montreal. Population-based data (The National Health and Nutrition Examination Survey) from 1999 to 2004 in the United States indicated that $10.6 \%$ of women between 20 and 29 years of age were seronegative for rubella (12).

Women who were 20 years of age and younger had the lowest levels of serological protection, as assessed by rubella serology (23.2\% seronegative), and IgG titres measured by the immunoassay (mean $34.6 \mathrm{U} / \mathrm{mL}$ ). In addition, the proportion of seronegative women 20 to 24 years of age increased from $10.3 \%$ in 2002 to $18.3 \%$ in 2005 . This trend is similar to a report from Newfoundland (13) where from 1991 to 2000, the incidence of seronegativity gradually increased in women 20 to 24 years of age, such that by the end of the study, their seronegative rate (19\%) was higher than those 15 to 19 years of age (15\%). Given that rubella titres wane over time in the absence of circulating wild virus, there will be a cohort effect representing the waning of vaccine-induced immunity among women who had received only one dose of vaccine (13). Almost all the women who were 20 to 24 years of age in the present study would have received only one dose of vaccine because the cohort who would have routinely received two doses were 12 to 15 years of age during the study. Another possibility for the high seronegativity in the women 20 to 24 years of age may be a high incidence of immigrants from countries without a rubella immunization program in this age group. Although rubella vaccine is recommended at the first physician contact for women of childbearing potential who arrive in Canada from countries with no rubella immunization program (14), compliance with this recommendation is undoubtedly low. The higher seroprevalence among older women may be a result of more durable IgG titres from natural disease combined with boosting from circulating virus than the titres resulting from immunization (7). It is also possible that older women were more likely to have received postpartum immunization. However, a similar trend of increasing seroprevalence with age was noted when only primigravid women were examined. As women born in Alberta after 1990 enter their child-bearing years, it is thought that the percentage of seronegative women in this 20 - to 24-year age group should decrease because most will have received two doses of rubella vaccine.

Specimens submitted from rural northern health regions were more likely to test negative for rubella immunity than specimens coming from other health regions. Although women from the northern region were significantly younger than women from the urban areas (26.2 years versus 28.9 years; $\mathrm{P}<0.001$ ), multivariate analyses (data not shown) indicated that even after controlling for this age difference, region was an independent correlate for seroreactivity. The proportion of immigrants in various health regions was not available for analysis to see whether immigration pattern played a role in the regional difference in seroreactivity. If infant and postpartum rubella immunization is more difficult to accomplish in these areas, strategies that offer immunizations when people access the health care system for other reasons (such as hospitalizations or postpartum visits) would need to be applied to improve the level of rubella immunity.
TABLE 4

Comparison of specimens with redundant versus nonredundant prenatal rubella screening in Alberta between August 1, 2002, and December 31, 2005

\begin{tabular}{lcccc}
\hline Variable & $\begin{array}{c}\text { Specimens, } \\
\mathbf{n}\end{array}$ & $\begin{array}{c}\text { Redundant } \\
\text { screening* }^{*}\end{array}$ & $\begin{array}{c}\text { Nonredundant } \\
\text { screening P }\end{array}$ & \\
\hline Total & 42,274 & $8,728(20.7)$ & $33,546(79.3)$ & - \\
Age, years & $42,151^{\dagger}$ & $28.4 \pm 5.3$ & $27.5 \pm 5.6$ & $<0.0001$ \\
Gravidity & $26,264^{\dagger}$ & $2.7 \pm 1.7$ & $2.5 \pm 1.7$ & $<0.0001$ \\
Parity & $25,293^{\dagger}$ & $1.2 \pm 1.3$ & $1.1 \pm 1.3$ & 0.0001 \\
Health region & & & & $<0.0001$ \\
Calgary & 13,297 & $2,733(20.6)$ & $10,564(79.5)$ & - \\
Edmonton & 12,030 & $2,716(22.6)$ & $9,314(77.4)$ & - \\
Northern Alberta & 8,637 & $1,466(17.0)$ & $7,171(83.0)$ & - \\
Southern Alberta & 8,310 & $1,813(21.8)$ & $6,497(78.2)$ & - \\
Year & & & & 0.035 \\
August - December & 5,273 & $1,131(21.4)$ & $4,142(78.6)$ & - \\
$\quad$ & & & & - \\
2002 & 12,369 & $2,630(21.3)$ & $9,739(78.7)$ & - \\
2003 & 10,759 & $2,182(20.3)$ & $8,574(79.7)$ & - \\
2005 & 13,876 & $2,785(20.1)$ & $11,091(79.9)$ & - \\
\hline
\end{tabular}

Data are represented as $n(\%)$ or mean $\pm S D$. *Redundant screening is defined as any woman having more than one positive rubella result with specimens submitted by the same physician; ${ }^{+}$Number of specimens of 42,274 , for which these data were recorded on the requisition

An examination of the subgroup of women who had multiple rubella screenings during the study period revealed a high level of redundant screening. In total, there were over 17,000 women who had multiple positive rubella screenings, representing over 20,000 specimens. Using a basic cost estimation of $\$ 9.00$ per rubella IgG test, which includes only reagents and staff time using an automated platform, the potential direct cost saving of not performing these redundant rubella $\operatorname{IgG}$ tests would be $\$ 180,000$. Approaches to reduce unnecessary tests and costs would include determining why physicians rescreen previously seropositive women, and educating physicians to examine previous laboratory results and to participate in the opt-out program - a process that is expedited by the increasing availability of electronic health care records. However, many physicians will continue to order the test rather than confirm previous results because this saves them time. A different and likely more effective approach would be to implement an algorithm at ProvLab that would automatically cancel repeat screenings on previously immune patients.

CRS can occur in infants born to women with previously documented natural or vaccine-induced immunity (7). Had waning immunity been recognized in a previous pregnancy, a booster dose of vaccine may have prevented the CRS. Moreover, the comparison of serial rubella titres may allow the identification of rubella infection early in pregnancy as indicated by a marked rise in IgG titre, allowing the mother to consider a therapeutic abortion. The current policy in Alberta is to administer a maximum of two doses of the rubella vaccine because of doubt about the efficacy of further doses. Some women who were previously seropositive but have waning immunity will have received only one dose, so they would qualify for the vaccine under the current program. The higher seroprevalence among older women may be a result of more durable IgG titres from natural disease than from immunization, combined with boosting from circulating virus 
(7). Currently, it is difficult to justify the costs involved in rescreening previously seropositive pregnant women in the absence of endemic rubella and in the absence of data demonstrating that a booster dose of vaccine is efficacious for previously vaccinated seronegative women.

One limitation of the study is that a small proportion of women in Alberta have no prenatal screenings. These are often women who live in suboptimal social situations, or object to the medical model of health care and refuse immunizations. Therefore, it is possible that the rubella seronegative rate would be higher in these women than in the general population. In addition, information on ethnicity and religion - factors associated with rubella nonimmune status in a study from Australia (15) and immunization rates per region - were not available for analysis in the current study.

\section{REFERENCES}

1. Lee JY,Bowden DS. Rubella virus replication and links to teratogenicity. Clin Microbiol Rev 2000;13:571-87.

2. Masuko-Hongo K, Kato T, Nishioka K. Virus-associated arthritis. Best Pract Res Clin Rheumatol 2003;17:309-18.

3. Koklu E, Kurtoglu S, Akcakus M, et al. Blueberry muffin syndrome owing to congenital rubella: Case report. Ann Trop Paediatr 2006;26:149-51.

4. Honeyman M. How robust is the evidence for viruses in the induction of type 1 diabetes? Curr Opin Immunol 2005;17:616-23.

5. Atreya CD, Mohan KV,Kulkarni S. Rubella virus and birth defects: Molecular insights into the viral teratogenesis at the cellular level. Birth Defects Res A Clin Mol Teratol 2004;70:431-7.

6. Robertson SE, Featherstone DA, Gacic-Dobo M, Hersh BS. Rubella and congenital rubella syndrome: Global update. Rev Panam Salud Publica 2003;14:306-15.

7. Robinson JL, Lee BE, Preiksaitis JK, Plitt S, Tipples GA. Prevention of congenital rubella syndrome - what makes sense in 2006? Epidemiol Rev 2006;28:81-7.

8. Weir E, Sider D. A refresher on rubella. CMAJ 2005;172:1680-1.

9. Ratnam S, West R, Gadag V, Williams B, Oates E. Rubella antibody

\section{CONCLUSIONS}

The clinical importance of the relatively high percentage of rubella seronegative pregnant women in Alberta remains to be established. The last cases of CRS diagnosed in the province occurred in $1998(7,8)$, but in the absence of endemic rubella, such cases may not occur even though some women are at risk. Reanalysis of similar data in five to 10 years should determine whether the introduction of a two-dose MMR vaccine schedule has increased measurable immunity. Efforts should be made to decrease the incidence of redundant screening for rubella immunity.

ACKNOWLEDGEMENTS: The authors thank the Canadian Institutes of Health Research for the summer studentship funding received by Dr Kearns.

levels in school-aged children in Newfoundland: Implications for a two-dose rubella vaccination strategy. Can J Infect Dis 1997;8:85-8.

10. Gyorkos TW, Tannenbaum TN, Abrahamowicz M, et al. Evaluation of rubella screening in pregnant women. CMAJ 1998;159:1091-7.

11. Gyorkos TW, Beliveau C, Rahme E, et al. High rubella seronegativity in daycare educators. Clin Invest Med 2005;28:105-11.

12. Hyde TB, Kruszon-Moran D, McQuillan GM, et al. Rubella immunity levels in the United States population: Has the threshold of viral elimination been reached? Clin Infect Dis 2006;43(Suppl 3):S146-50.

13. Health Canada. Proceedings of a meeting of the expert advisory group on rubella in Canada. Can Commun Dis Rep 2002;28(S4):1-24.

14. Public Health Agency of Canada. Canadian Immunization Guide, 7th edn, 2006.

15. Francis BH, Thomas AK, McCarty CA. The impact of rubella immunization on the serological status of women of childbearing age: A retrospective longitudinal study in Melbourne, Australia. Am J Public Health 2003;93:1274-6. 


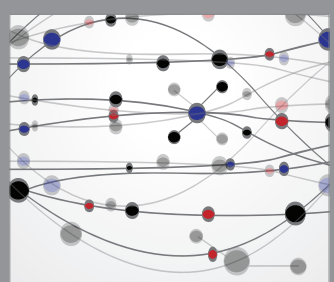

The Scientific World Journal
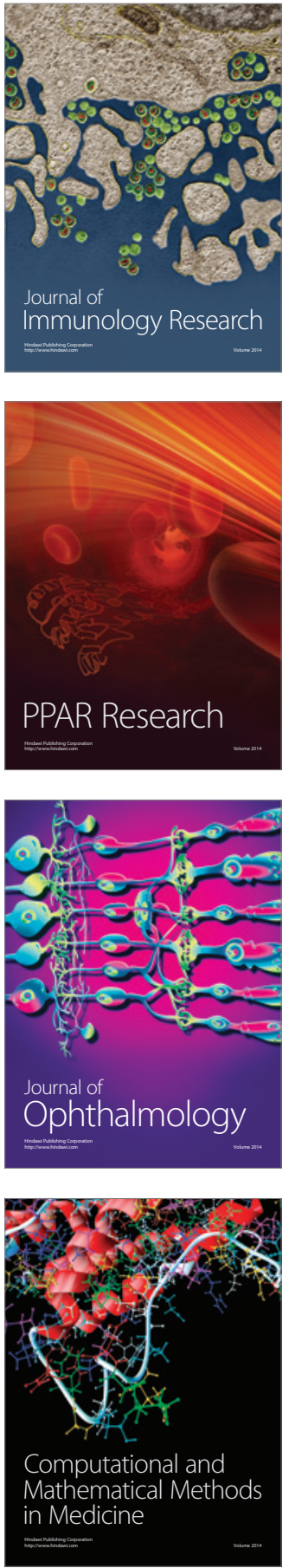

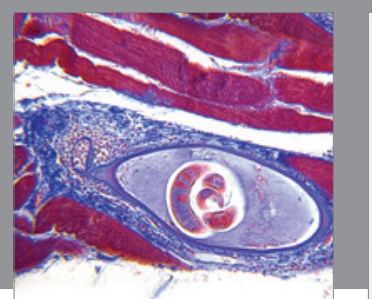

Gastroenterology Research and Practice

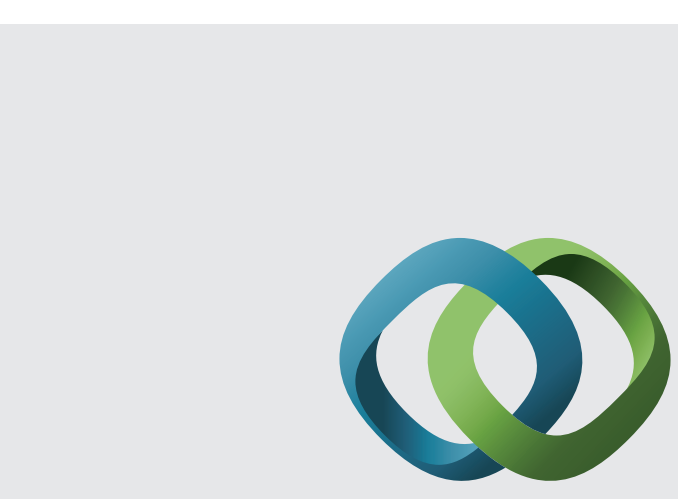

\section{Hindawi}

Submit your manuscripts at

http://www.hindawi.com
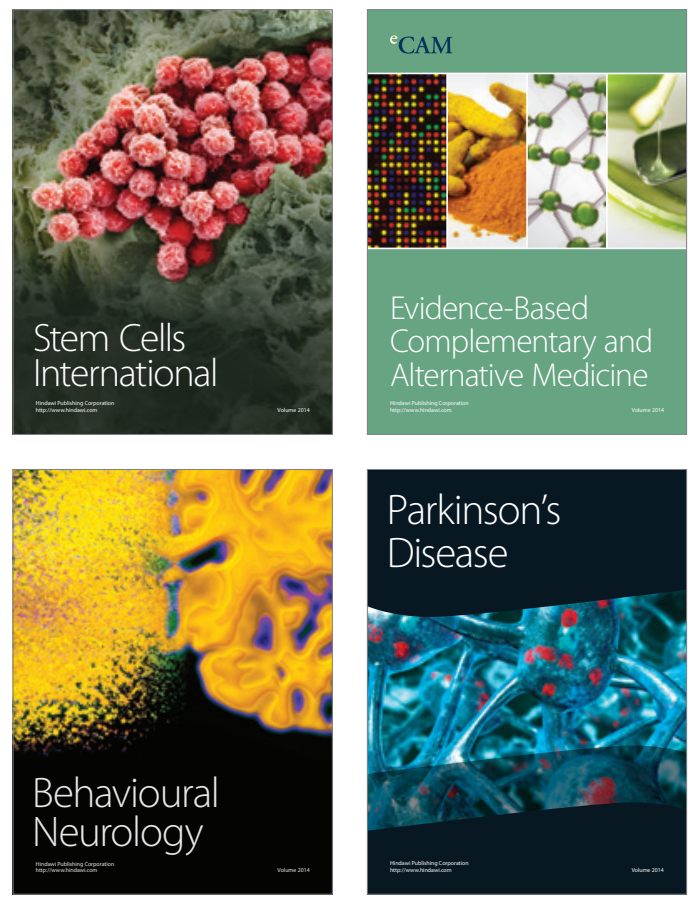
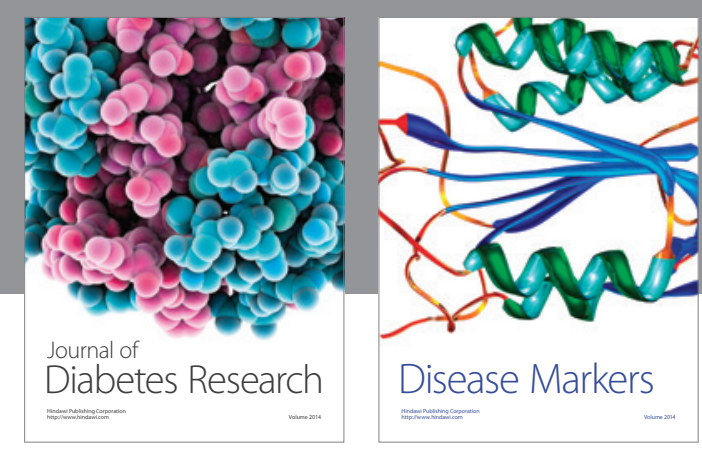

Disease Markers
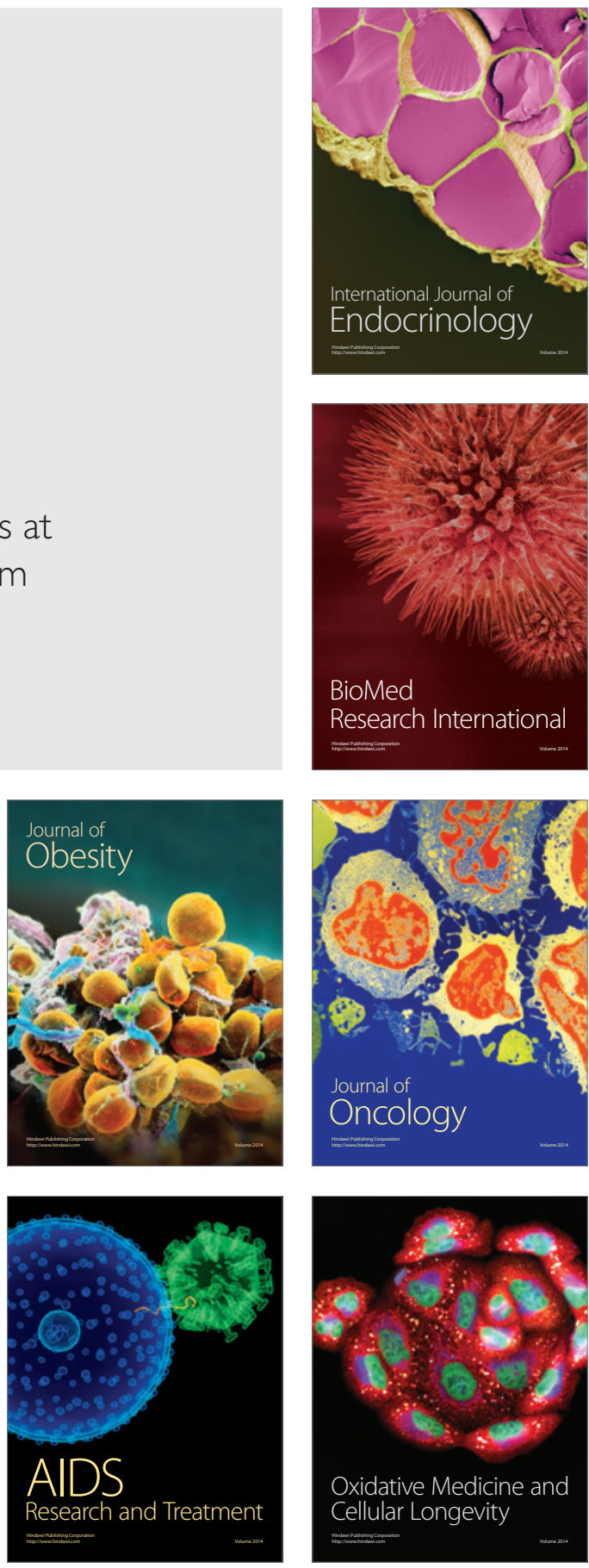